\title{
How Fiscal Policy in Bulgaria may Affect the Transition to a Low Carbon Economy?
}

\section{Dimitar Zlatinov}

\section{Summary}

The adaptation of traditional macroeconomic policy goals to new ecological realities assigns a specific role to macroeconomic policy. We model the short-run transmission mechanism of fiscal policy under Currency Board Arrangements in Bulgaria in order to assess the fiscal policy potential to boost sustainable economic development and compensate for the economic growth losses due to decarbonisation of the economy. We find that fiscal policy instruments in Bulgaria have no statistically significant effect on GDP components considered separately but they do have a complex effect on macroeconomic environment in the country. This indicates that specific fiscal policy effects to support the transition to a low-carbon economy in Bulgaria cannot be expected and the structural policies should be followed.

Keywords: fiscal policy, transition to a low-carbon economy, Currency Board Arrangements

JEL: E62, Q01, Q58

\section{Introduction}

Gobally a lot of initiatives are being Zlaunched to build a new economic model that focuses on sustainable development rather than on the traditional goal of macroeconomic policy of accelerating economic growth. The UN Agenda 2030 contains 17 Sustainable Development Goals such as responsible consumption and production, clean water and energy, and mobilization of sustainable cities and communities through increased industry, innovation, and infrastructure. In the end of 2019, the European Commission proposed the European Green Deal as a new growth strategy that brings together four dimensions: environment, productivity, stability and fairness. The Annual Sustainable Growth Strategy aims to put the emphasis on competitive sustainability and achievement of the United Nations' Sustainable Development Goals. The EU Member States should identify synergies and trade-offs between environmental, social and economic policies at national level while their progress will be monitored via a SDG indicators set.

However, the Simon Kuznets' ecological curve (Kuznets, 1955) illustrates the empirical evidence that when an economy is growing there is an increase in environmental damages. The 2018 Report of the Club of Rome states: "More human economy (more people and commodities) means less natural ecosystem. There is an obvious physical conflict between the growth of the economy and the preservation of the environment." ( $p$.

Dimitar Zlatinov, PhD, Associate Professor, Sofia University St. Kliment Ohridski, Faculty of Economics and Business Administration and Economic Research Institute at Bulgarian Academy of Sciences= 


\section{Articles}

68). Higher economic prosperity means more greenhouse gas emissions and resource consumption (Chancel\&Piketty, 2015). This raises the issue of how economic development can be adapted to the sustainable development and traces macroeconomic dimensions of the transition to a low-carbon economy (Ivanova\&Chipeva, 2019).

Theadaptation of traditionalmacroeconomic goals to new ecological realities assigns a specific role to macroeconomic policy. The fundamental macroeconomic goals such as balanced economic growth, high employment, and price stability should be complemented by a commitment to improve public well-being in ecological terms. The drop in economic growth due to a low-carbon economy transition pose challenges to fiscal and monetary policies in terms of providing financial resources to limit and tackle the potential adverse effects.

The paper examines the potential of the fiscal policy in Bulgaria to boost sustainable economic development and limit the negative economic effects considering the specificities of the Currency Board Arrangements. Our purpose is to assess the extent to which government intervention in Bulgaria can compensate for the decline in economic growth due to the decarbonisation of the economy by stimulating aggregate demand in the short run. We employ a standard macroeconomic approach that relies on Keynesian and non-Keynesian effects in modelling the transmission mechanism of fiscal policy in the short run considering the specificities of the macroeconomic policy framework in Bulgaria. We focus on 20082018 period when the Bulgarian economy was affected by the 2007-2008 global financial and economic crisis but has progressively recovered since then. We study different phases of the business cycle and show the potential of the fiscal policy in Bulgaria on the eve of the policy debate on the environmental aspects of economic development set by the European Green Deal. Thus, the challenges facing the country's macroeconomic management due to ecological transition can be outlined in addition to the need for reforms with a view to joining the euro area.

The paper begins with an overview of economic research on short-run and longrun economic effects that can be expected in countries like Bulgaria due to the transition to a low-carbon economy. In order to assess the potential of fiscal policy to affect economic development, we focus on its transmission mechanism on GDP in the short run under Currency Board Arrangements in Bulgaria. Thus, the study reflects the specificities of macroeconomic policy in analyzing the aspects of the ecological transition in a developing country such as Bulgaria ${ }^{1}$. On this basis we make conclusions about the role of the Bulgarian governmental policy to accelerate the transition to a low-carbon economy and mitigate its negative economic effects.

Theoretical and empirical aspects of ecological transition: is sustainable development compatible with the catching up of the Bulgarian economy?

Bulgaria ranks third in the EU in the production of harmful carbon dioxide emissions and the share of coal in the country's electricity mix was $43 \%$ by 2017 according to Eurostat. In the 2020 European Semester Country Report for Bulgaria the European Commission pointed out that "The high carbon and energy intensity of Bulgaria's economy and its high dependence on coal power call for significant transition efforts" (EC 2020, p. 61). The inefficient use of energy affects adversely the competitiveness of the Bulgarian economy and the falling life standard. Bulgaria is also a less resource

\footnotetext{
${ }^{1}$ For policy implications for euro area countries see Magazzino, C., (2017) and Magazzino, C., (2016).
} 


\section{Articles}

productive economy (the ratio between the GDP and domestic consumption) in the European Union and the difference with the average EU levels is more than 6 times. The process of effective energy transformation would cost the loss of economic growth and jobs in the country.

Figure 1. Resource productivity (Euro per kilogram, chain linked volumes, 2010)

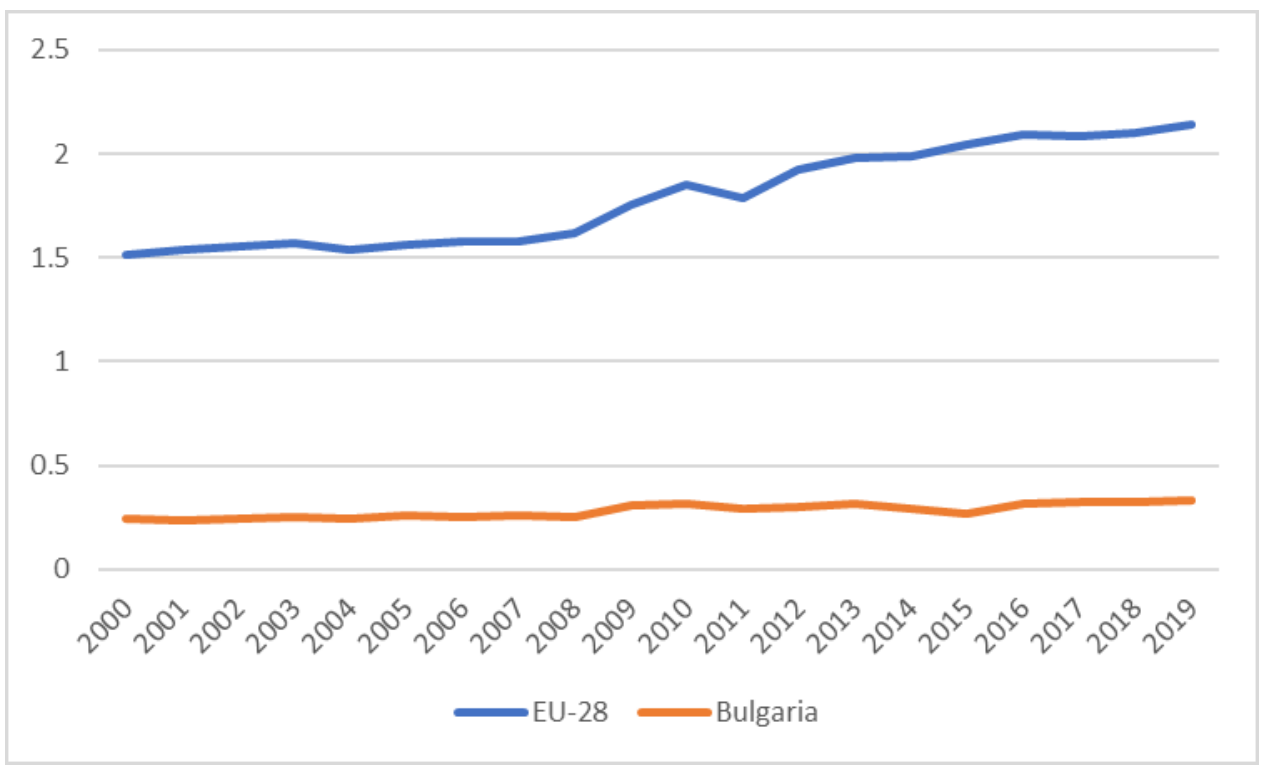

Source: Eurostat.

In the short run we expect the following negative effects on sectoral activity:

- The replacement of fossil fuels with biofuels would lead to a significant change in the energy mix. As a result, coal-fired power plants will be closed, unemployment levels will go up, and the employment in the Bulgarian energy sector will be restructured. The cost of electricity will increase and, consequently, a direct effect on energy poverty in Bulgaria will be visible. The energy poverty in Bulgaria is the highest across the EU according to Eurostat (nearly $60 \%$ of poor households had difficulty maintaining an adequately high temperature in their households in the winter of 2017) while energy justice is a rallying cry to tackle energy poverty (Labelle\&Georgiev, 2015).

- The use of fertile land and forests to produce biofuels may put pressure on the agricultural sector in Bulgaria and further limit the local production of fruits and vegetables (BeluhovaUzunova, Shishkova\&Ivanova, 2019).

- New requirements in the construction sector related to the so called "green buildings" with high energy efficiency could increase production costs and real estate prices.

- Globally, the transport sector leads to about $30 \%$ of carbon pollution. The shift towards electro mobiles is an inevitable measure for sustainable development. The use of electric cars in Bulgaria is still limited due to the low levels of income. The Bulgarian Na- 
tional Framework for the Development of the Market for Alternative Fuels in the Transport Sector reports between 35,000 in 2020 and 130,000 in 2030 electro mobiles in the country. The increase of electricity prices due to limiting use of coals in its production will lead to an additional increase in this type of transport. The new European regulations for its more widespread use would lead to a shrinkage of the transport sector in Bulgaria that is already subject to various restrictions, especially internationally.

- The 2018 Club of Rome Report proposes reforming WTO rules and imposing tariffs on trade in goods and services which causes environmental damage. The adoption of such restrictions would limit the import of investment goods and services used in local production while the Bulgarian competitiveness on foreign trade markets would be affected by rising energy prices.

- Encouraging green investment based on environmental, social or management criteria could put pressure on the investment plans of Bulgarian financial institutions and result in the decline in prudent lending to some sectors (Zhelyazkova, 2017).

- Some proposals for an internationally harmonized but nationally imposed carbon tax would have a direct effect on Bulgarian industry and would eliminate all financial incentives for the fossil fuel industry. The contradictory effects of such taxation to limit greenhouse gas emissions are highlighted in a study about Australia (AsafuAdjaye\&Mahadevan, 2013).

In the long run the transition to a low carbon economy causes higher resource efficiency through technological progress, innovation, and employment restructuring. Achieving greater resource efficiency is a prerequisite for a continuous increase in the economic growth rates during the transition to sustainable development which is completely in line with the neoclassical growth model of Robert Solow (Rangelova, 2009). Higher efficiency of energy utilization would result in increased competitiveness and more jobs in the developed Western European countries such as Finland, France, the Netherlands, Spain, and Sweden (Wijkman\&Skånberg, 2016). When one considers high income countries, economic growth should not be viewed as "victim" of improved resource efficiency but rather as a prerequisite for accelerating it (McDonough\&Braungart, 2013). However, one should also bear in mind that technology penetration into developing countries is directly dependent on their acceleration in developed ones (Zlatinov, 2018). Such a lag would further prolong the long-term effects of the ecological transition and short-run losses can be essential for countries like Bulgaria.

The differences between the short-run and long-run effects of the transition to a low-carbon economy on economic growth make the role macroeconomic policies have in neutralizing the negative effects and boosting the positive ones crucial. A study for China finds that the limit of $7 \%$ annual economic growth turns out to be critical for mitigating such negative spill-overs ( $\mathrm{Li}$ et al., 2018). Therefore, we aim at assessing the fiscal policy potential to affect GDP in Bulgaria. Our purpose is to assess the extent to which government intervention in Bulgaria can compensate for the decline in economic growth due to the decarbonization of the economy by stimulating aggregate demand. In a similar way, the role of macroeconomic policy in adapting the Polish economy as one 


\section{Articles}

of the EU countries with the largest share of coal in its energy mix to the new realities in the field of the usage of energy resources has been studied by Christoph Böhringer and Thomas Rutherford (2013).

\section{Modelling the transmission mechanism of fiscal policy in the short run}

The methodological approach to studying the fiscal policy potential in Bulgaria under transition to a low-carbon economy is based on modelling its transmission mechanism in the short run. The modelling of the transmission mechanism of fiscal policy considers the specificities of the Currency Board Arrangements, the available governmental policy instruments, and the explicitly declared goals of macroeconomic policy. This makes it possible to track the direct effects of fiscal policy on GDP. Deriving the transmission mechanism of fiscal policy based on the Keynesian short-term methodological approach allows adhering to established macroeconomic concepts and following a strict theoretical framework. We strive for all the described dependencies at the macroeconomic level to be empirically tested so that the applied nature of the study to be demonstrated.

When modelling the fiscal policy transmission mechanism, we consider Keynesian and non-Keynesian effects. The Keynesian effects are associated with the Keynes' thesis that increase in government spending stimulates economic activity and raises national income. The non-Keynesian effects highlight the negative consequences of active government policy for interest rates, exchange rates, and household wealth, including the Ricardian equivalence by Barro (1974).

Following the Keynesian modelling method, we trace the direct fiscal effects on GDP $(P Y)$ through the components of aggregate demand $(A D)$ :
$P Y=A D=C+I+G+N X$

where $C$ is individual consumption, $I$ is gross fixed capital formation, $G$ is general government consumption, and $N X$ is net exports.

We define the individual consumption function considering that in an open economy the households use the private gross national disposable income $\left(G N D I^{P}\right)$ :

$C=C_{0}+c G N D I^{P}$

where $C_{0}$ is the autonomous consumption and $c$ is the marginal propensity to consume.

We model the private gross national disposable income as a difference between the gross national disposable income (GNDI) and the government gross national disposable income $\left(G N D I^{G}\right)$ :

$G N D I^{P}=G N D I-G N D I^{G}$

The gross national savings $(S)$ can be calculated in two ways:

- gross national disposable income (GNDI) minus final consumption expenditure $(C+G)$;

- the sum of private savings $\left(S_{p}\right)$ and government savings $\left(S_{g}\right)$ :

$S=G N D I-(C+G)=S_{p}+S_{g}$

Private savings $\left(S_{p}\right)$ are the difference between the private gross national disposable income $\left(G N D I^{P}\right)$ and individual consumption $(C)$ while government savings $\left(S_{g}\right)$ equal the budget balance $(B S)$. Hence, government gross national disposable income $\left(G N D I^{G}\right)$ is: $G N D I^{G}=S_{g}+G$

Based on the same transformations, private gross national disposable income amounts to:

$G N D I^{P}=G N D I-B S-G$

When we model the individual consumption we consider the tradeoff between consumer savings and interest rate on deposits $\left(i^{s}\right)$. Following the Ricardian equivalence (Barro, 
1974) we also model the tradeoff between individual consumption and tax rate $(t a)$. The aggregate individual consumption function is:

$C=C O+c(G N D I-B S-G)+c_{1} i^{s}+c_{2}$ ta

where $c_{1}<0$ and $c_{2}<0$.

Gross fixed capital formation can be divided into private investment $\left(I_{p}\right)$ and government investments $\left(I_{g}\right)$ :

$I=I_{p}+I_{g}$

Like the way we model the individual consumption, we assume that private investments depend on tax policy and interest rates on loans $\left(i^{c}\right)$. Therefore, we model the gross fixed capital as follows:

$I_{g}=I_{p_{t}}-i_{1} i^{c}{ }_{t}-i_{2} t a_{t}+I_{g_{t}}$

where $i_{1}<0$ and $i_{2}<0$ assuming that an increase in corporate tax rates leads to negative effect on corporate profits.

Government spending $(G)$, including the spending needed for adapting the economy to decarbonization, depends directly on the fiscal policy pursued. According to the non-Keynesian effects, active government intervention is the reason for limiting private investment that is called crowding out effect (Hemming et al., 2002). We assume that the crowding out effect depends on government bond yields and country risk premium $(r b)$. Following the Dornbusch's approach (Dornbusch, 1984) we model the country risk premium as a function of the budget balance and real GDP:

$r b=r b_{1} B S+r b_{2} Y$

Thus, the effect of fiscal policy on real interest rate $(R)$ is given as follows:

$R=R_{0}+r b_{1} B S+r b_{2} Y$

where $R_{0}$ is the natural real interest rate.

To sum up, the identified channels of fiscal policy impact on GDP in the short run are:

$$
\mid \begin{aligned}
& Y=C+I+G+N X \\
& C=C_{0}+c(G N D I-B S-G)-c_{1} i^{s}+c_{2} t a \\
& I=I_{p}-i_{1} i^{c}-i_{2} t+I_{g} \\
& R=R_{0}+r b_{1} B S+r b_{2} Y
\end{aligned}
$$

The system of equations (12) indicates the direct effects of fiscal policy instruments on individual consumption and gross fixed capital formation as well as the indirect effects through the impact on real interest rate. Using these equations, we can test how the fiscal policy instruments can compensate for and mitigate the possible negative effects of the transition to a low-carbon economy in Bulgaria.

\section{Assessing the fiscal policy potential} to affect the transition to a low-carbon economy in Bulgaria

The research approach is operationalized through an econometric assessment of the dependencies between macroeconomic indicators in accordance with the derived transmission mechanism of fiscal policy. We employ Ordinary Least Squares (OLS) method to estimate coefficients and parameters of a linear regression model we have developed in the previous section. Inevitably, this imposes certain limitations on the study, assumptions about the economic nature of the observed phenomena, as well as purely technical features related to the use of regression analysis.

First, we estimate the dependence of individual consumption on fiscal parameters in the following regression form according to equation (7) in the previous section:

$C_{t}=\beta_{0}+\beta_{1} G N D I_{t}+\beta_{2} B S_{t}+\beta_{3} G_{t}+\beta_{4} i^{s}{ }_{t}+\beta_{5} t a_{t}+e_{t}$

The data we use is seasonally adjusted and deflated by the deflator of individual consumption. We have 44 observations in the first quarter of 2008 - fourth quarter of 2018. In our initial estimations we found perfect multicollinearity between individual consumption and tax rate which made it necessary to exclude it. In logarithmic form, the equation (13) is presented as follows: 


$$
\begin{aligned}
\log C_{t}= & \begin{array}{c}
65.9164 \\
(0.00969)
\end{array}+\underset{(0.00710)}{0.6252} \log G N D I_{t}+\underset{(0.029505)}{0.2067} \log B S_{t}+\underset{(0.00671)}{0.2727} \log G_{t}+ \\
& \begin{array}{ll}
0.6524 \\
(0.974)
\end{array} \operatorname{logi}^{s}{ }_{t}+e_{t}
\end{aligned}
$$

Adjusted R-squared: 0.7457

F-statistics: 137

$\mathrm{DW}=2.1112$

Studentized Breusch-Pagan test: $p$-value $=0.1204$ Variance Inflation Factor:

$\log$ NDII $_{t}: 3.008652 \quad \log G_{t}: 1.809154$

$\log B S_{t}: 1.361019$

$\log i_{t}^{s}: 2.557017$

Following our estimations in $\mathrm{R}$ Studio, we find that $1 \mathrm{pp}$. change in budget balance and government spending in Bulgaria results respectively in 0.21 p.p. and 0.27 p.p. change in individual consumption. The low sensitivity of individual consumption to direct fiscal policy instruments in Bulgaria is an indicator of the functiong of automatic stabilizers such as social expenditures. As the experience of the global financial and economic crisis of 2008 shows, despite the initial decline in 2009, final consumer spending has shown some resilience since 2010 and can be seen as a buffer for maintaining the dynamics of domestic demand in different phases of the economic cycle. To some extent, this process assigns a certain specific role to Bulgarian fiscal policy in terms of rising social spending to maintain private consumption. Such a conclusion is expected under the Currency Board Arrangements in Bulgaria and demonstrates the limited role of discretionary government actions in the real sector.

We also test the validity of the crowding out effect in Bulgaria on the basis of equation (11) in the following regression form:

$R_{t}=\beta_{0}+\beta_{1} B S_{t}+\beta_{2} Y_{t}+e_{t}$

We use seasonally adjusted GDP data at 2010 prices and data for the 2004-2018 budget balance. However, we used various transformations of the regression equation, its statistical properties did not improve significantly and the results of the regression analysis are as follows:

$$
\begin{aligned}
R_{t}= & \underset{(0.08283)}{-0.8314}-\frac{0.00007205}{(0.53446)} B S_{t}- \\
& -\underset{(0.00222)}{0.00007949} Y_{t}+e_{t}
\end{aligned}
$$

Adjusted R-squared: 0.1396

F-statistics: 5.785

DW $=0.058653$

Studentized Breusch-Pagan test: $\mathrm{p}$-value = 0.0018505

Breusch-Godfrey test: $\mathrm{p}$-value $=0.0048114$

Variance Inflation Factor:

$B S_{t}: 1.012535$

$Y_{t}: 1.012535$

The trade-off between the real interest rate and the GDP is statistically significant but it is almost 0 . The statistical tests performed in the regression estimation of equation (16) show the presence of autocorrelation, as well as heteroskedasticity. The results cannot be considered reliable possibly due to the data used and assumptions made. Thus, we cannot conclude that there is a negative effect on the interest rate in Bulgaria when budget deficit grows. This conclusion is to some extent expected under Currency Board Arrangements and endogenous money supply in the country. Moreover, it is a signal that government's discretionary actions do not adversely affect the investment climate in Bulgaria which may be a prerequisite for accelerating the private sector transition to a low carbon economy. 
Finally, we estimate the total impact of fiscal policy on Bulgarian GDP using the following regression equation:

$P Y_{t}=\beta_{0}+\beta_{1} B S_{t}+\beta_{2} t a_{t}+\beta_{3} r b_{t}+\beta_{4} \Delta G D_{t}+e_{t}$

According to the so-called snow-ball effect we assume an inverse relation between the budget surplus $(B S)$ and the change in general government debt $(\Delta G D)$. The higher the budget surplus and the economic growth is the lower the interest rate on general government debt is (Lojsch, RodriguezVives\&Slavik, 2011). However, government spending $(G)$ and government investments $\left(I_{g}\right)$ are components of nominal GDP and we exclude them from the econometric estimation of equation (17). We use data in the first quarter of 2003 - fourth quarter of 2018.

$$
\begin{gathered}
\left.\log P Y_{t}=\begin{array}{c}
1.2028 \\
(0.00869)
\end{array}-\begin{array}{c}
0.15267 \\
(0.0558)
\end{array}\right) \log B S_{t}-\begin{array}{c}
0.349 \\
(0.0177)
\end{array}{\log t a_{t}-}_{(0.0109)} \operatorname{logr}_{t}- \\
0.2845 \\
(0.5801)
\end{gathered}
$$

Adjusted R-squared: 0.7595

-statistics: 7.808

$\mathrm{DW}=1.82604$

Studentized Breusch-Pagan test: p-value = 0.053317

Variance Inflation Factor:

$$
\begin{aligned}
& \log B S_{t}: 1.120897 \\
& \log t a_{t}: 1.261467 \\
& \log r d_{t}: 1.151953 \\
& \log r b_{t}: 1.276497 \\
& \log \Delta G D_{t}: 1.355152
\end{aligned}
$$

The only statistically insignificant variables are the budget balance and the change in the government debt. The changes in tax rates and government bond yields have a direct effect on the nominal GDP in Bulgaria. Having in mind the results we have already presented, we may conclude that fiscal policy instruments have no statistically significant effect on components of the GDP considered separately but they do have a complex effect on the macroeconomic environment. The low direct tax rate is a precondition for increasing the country's competitiveness and attracting foreign investors (Tassev\&Nestorov, 2017), as well to "lighten up" the economy. However, the results in this direction are often questionable. In recent years, the low degree of reinvestment of the profits of
Bulgarian enterprises and the high share of repatriated profits of foreign enterprises in the country (in 2019 the investment income exported from the country amounted to $4.8 \%$ of GDP) are becoming more of a trend. The low tax rate on direct taxes also creates a strong cyclical dependence of budget revenues on consumption and imports in the country, which are subject to indirect taxes, and limits the government's ability to pursue counter-cyclical policies. This is indicative of the indirect channels of fiscal policy that has a stronger impact on GDP than the expected theoretical trade-offs for economies which do not operate under Currency Board Arrangements. Fiscal stability also matters while government bond yields largely reflect the overall macroeconomic performance. These results demonstrate the atypical nature of Bulgarian fiscal policy.

Therefore, the government intervention should be more concerned with structural reforms that have the greatest potential to affect the overall economic performance (Petranov, 2016). The conclusions drawn are also supported by the low fiscal multiplier in Bulgaria that suggests a modest effect on GDP when fiscal spending increases. According to Kristina Karagiozova-Markova 


\section{Articles}

et al. (Karagyozova-Markova, Deyanov \& Iliev, 2013) the fiscal multiplier in Bulgaria varies between 0.17 and 0.41 . The low fiscal multiplier is mainly due to the small size of the Bulgarian economy and its high openness under Currency Board Arrangements (openness of the economy was $124 \%$ in 2019). Other factors that affect fiscal multipliers in Bulgaria in terms of external influences, cyclical effect, money supply effect and velocity of money are further analysed in Ignatov (2016). These limitations clearly show that Bulgarian fiscal policy has no distinguished potential for real economic impact, and it performs primarily social functions. This once again emphasises its limited role in the transition to a low-carbon economy.

\section{Conclusion}

Although sustainable economic development has a positive impact in the long run, in the short run it poses some challenges that developing countries like Bulgaria should tackle. This raises the issue whether demand management policies can be effective and support the ecological transition. We find that in the short run fiscal policy instruments in Bulgaria, considered separately, do not have a statistically significant effect on the components of nominal GDP and they cannot play a specific role in the transition to a lowcarbon economy. The current tax policy of the Bulgarian government does not influence the consumer and investment behaviour which may be due to the flat tax rate introduced in 2008. We do not find evidence of a significant crowding-out effect and private investments are insensitive to changes in interest rates due to changes in the budget balance. Taken together, however, tax policy and the government bonds yields have a statistically significant effect on nominal GDP. This is an indicator of the indirect channels of fiscal policy instruments under Currency Board
Arrangements which should be considered when one assesses the government's capacity to support the transition to sustainable development in Bulgaria. The fiscal policy impact on GDP depends much more on the general economic environment and the overall macroeconomic situation of the country than on traditionally considered channels. This indicates that specific fiscal policy effects to support the transition to a low-carbon economy cannot be expected. The role of the government in creating a new model of sustainable economic development will depend on the overall economic environment in Bulgaria which make the structural policies crucial.

The macroeconomic management in Bulgaria can support the transition to a low-carbon economy through supply-side policies such as easing business conditions, supporting more flexible labour markets and improving institutional quality and governance. These measures have a long-lasting effect while in the short run fiscal policy potential to influence individual consumption and investments seems to be limited. Thus, linking the parameters of government spending policy with specific reforms to increase the efficiency of the use of budget funds in various areas, including green economic development, would make it possible for fiscal policy in the country not to be seen as a budgeting process but as macroeconomic policy that creates preconditions for sustainable development.

\section{References}

Asafu-Adjaye, J., R. Mahadevan (2013). Implications of $\mathrm{CO} 2$ reduction policies for a high carbon emitting economy. Energy Economics, Vol. 38, pp. 32-41

Barro, R. (1974). Are government bonds net wealth? Journal of Political Economy, Vol. 82, No. 6, pp. 1095-1117 
Beluhova-Uzunova, R., M. Shishkova, B. Ivanova (2019), Concepts and Key Sectors of the Bioeconomy, Trakia Journal of Sciences, Vol. 17, Suppl. 1, pp. 227-233

Böhringer, C., T. Rutherford (2013). Transition towards a low carbon economy: a computable general equilibrium analysis for Poland. Energy Policy, Vol. 55, pp. 16-26

Chancel, L., T. Piketty (2015). Carbon and inequality: from Kyoto to Paris. Paris School of Economics

Dornbusch, R. (1984). External debt, budget deficits and disequilibrium exchange rates. MIT Working Paper No. 347, pp. 1-53

European Commission (2020), 2020 European Semester: assessment of progress on structural reforms, prevention and correction of macroeconomic imbalances, and results of in-depth reviews under Regulation (EU) No 1176 (2011)

Hemming, R., M. Kell, S. Mahfouz (2002). The effectiveness of fiscal policy in stimulating economic activity - review of the literature. IMF Working Paper 02/208

Ignatov, I. (2016). Fiscal multiplier - a keystone for the attainment of the macroeconomic goals in Bulgaria. Proceedings of the International Scientific Conference "Economic Challenges: Migration, Globalization, Sustainability, Policies". University of National and World Economy, pp. 341-350 (in Bulgarian)

Ivanova, V., Chipeva, S. (2019). Transition to a circular economy model in the European Union - state and outlook. International E-Journal of Advances in Social Sciences, Vol. V, No. 14

Karagyozova-Markova, K., G. Deyanov, V. Iliev (2013). Fiscal policy and economic growth in Bulgaria. BNB Discussion Papers, No. 90

Kuznets, S. (1955). Economic growth and income inequality. American Economic Review, Vol. 49, pp. 1-28
Magazzino, C., (2017), Is per capita energy use stationary? Time series evidence for the EMU countries, Energy, Exploration \& Exploitation, Vol. 35, Issue 1, pp. 24-32

Magazzino, C., (2016), Is per capita energy use stationary? Panel data evidence for the EMU countries, Energy, Exploration \& Exploitation, Vol. 34, Issue 3, pp. 440-448

Labelle, M., A. Georgiev (2015), The sociopolitical capture of utilities: the expense of low energy prices in Bulgaria and Hungary. Energy Law and Energy Infrastructure Development for a Low-Carbon World Edition, Cambridge University Press

Li, Y., Y. Wei, S. Shan, Y. Tao (2018). Pathways to a low-carbon economy: Estimations on macroeconomic costs and potential of carbon emission abatement in Beijing, Journal of Cleaner Production, Vol. 199, pp. 603-615

Lojsch, D., M. Rodriguez-Vive, M. Slavik (2011), The size and composition of government debt in the Euro Area, Occasional Paper Series No. 132

McDonough, W., M. Braungart (2013). The Upcycle. Beyond Sustainability, Designing for Abundance, North Point Press, New York

Petranov, St. (2016), Sustainable economic development through sustainable economic policy: Is Bulgaria ready for a reindustrialization policy? Journal of Varna University of Economics, 4/2016 (in Bulgarian)

Rangelova, R. (2009), Changing determinants of the economic growth - theoretical base and specifics of the empirics. Economic Studies Journal, Volume 2, Bulgarian Academy of Sciencies, Economic Research Institute, ISSN 0205-3292, pp. 3-32 (in Bulgarian)

Tassev, A., N. Nestorov (2017). The Export potential of Bulgarian productions and the economic growth. Reports from the Eighth International Scientific Conference "Economics in changing world - national, regional and global dimensions". Varna 
Articles

University of Economics, pp.152-156 (in Bulgarian)

von Weizsäcker, E., A. Wijkman (2018). Come on! Capitalism, Short-termism, Population and the Destruction of the Planet. Club of Rome

Wijkman A, K. Skånberg (2016), The circular economy and benefits for society: jobs and climate clear winners in an economy based on renewable energy and resource efficiency: a study pertaining to the Czech Republic and Poland. Winterthur. Club of Rome
Zhelyazkova, V. (2017), Introduction to the circular economy (financing, accounting, reporting), ISBN 978-954-8590-51-8 (in Bulgarian)

Zlatinov, D. (2018), Macroeconomic challenges for the transition to the Economy 4.0 in Bulgaria (pp. 153-163), The Scientific Papers of the University of National and World Economy, Volume 3, Sofia, ISSN 2534-8957 